\title{
Does cognitive impairment in Parkinson's disease result from non-dopaminergic lesions?
}

\author{
BERNARD PILLON, BRUNO DUBOIS, GIULIANA CUSIMANO, \\ ANNE-MARIE BONNET, FRANÇOIS LHERMITTE, YVES AGID
}

From the Clinique de Neurologie et Neuropsychologie and INSERM U.289 Hôpital de la Salpêtrière, Paris, France

SUMMARY In order to investigate the neuronal basis of cognitive disorders in Parkinson's disease, the neuropsychological performance of 120 patients with idiopathic Parkinson's disease was analysed in relation to motor symptoms as a function of their response to levodopa. Cognitive impairment was poorly correlated with akinesia and rigidity, symptoms which respond well to levodopa treatment, and was not correlated at all with that part of the patients' motor score that could be improved by the drug. In contrast, strong correlations were found between all neuropsychological test scores and axial symptoms such as gait disorder and dysarthria, which respond little if at all to levodopa treatment. The neuropsychological test scores were also strongly correlated with the motor score of patients estimated when clinical improvement was maximal under levodopa treatment. This score is assumed to represent residual non-dopaminergic motor dysfunctions. The correlations suggest that much of the cognitive impairment in Parkinson's disease results from the dysfunction of non-dopaminergic neuronal systems.

Intellectual impairment is a well-established concomitant of Parkinson's disease, ${ }^{1-3}$ although the precise physiopathological basis of the deficits remains poorly understood. ${ }^{4}$ The possibility that deficient dopaminergic transmission in the central nervous system is responsible for some of these cognitive disorders has been postulated on the basis of the following evidence: improved performance on neuropsychological tests has been observed after levodopa treatment, ${ }^{5-7}$ or during "on" periods in patients with on-off fluctuations; ${ }^{8}$ significant correlations were found between various neuropsychological disturbances and Parkinsonian motor disability ${ }^{19}$ resulting from central dopaminergic lesions; ${ }^{10}$ similar cognitive disturbances have been demonstrated in MPTP-induced Parkinsonism, ${ }^{11}$ a well documented model of selective destruction of dopaminergic neurones in the substantia nigra. ${ }^{1213}$

The dopaminergic hypothesis of cognitive dysfunction in Parkinson's disease ${ }^{14}$ is, however, still controversial. The beneficial effect of levodopa on cognitive functions has been observed only at early

Address for reprint requests: Dr Yves Agid, Hôpital de la Salpêtrière, 47 Boulevard de l'Hôpital, 75651 Paris, Cedex 13, France.

Received 21 June 1988 and in revised form 24 September 1988. Accepted 27 September 1988 stages of the disease, ${ }^{15}$ and is more likely the reflection of a general increase in altertness, the so-called awakening effect, ${ }^{1617}$ or changes in affective state, ${ }^{718}$ than an improvement in specific cognitive operations. Furthermore, Rafal and his collaborators ${ }^{19}$ were unable to detect an amelioration of cognitive function in Parkinsonian patients after levodopa treatment. This suggests that neuropsychological deficits do not result from dopaminergic lesions.

In order to investigate the neuronal basis of cognitive disorders in Parkinson's disease, correlations were sought between performance on tests of a wide range of neuropsychological functions and Parkinsonian motor symptoms. The motor symptoms were treated according to their presumed relationship with dopaminergic lesions in the brain. Firstly, for the purpose of analysis, two types of motor symptoms were distinguished: those which are improved by levodopa treatment (akinesia, rigidity, tremor); those which respond little, if at all, to dopamine replacement therapy (gait disorders and dysarthria), and which may, therefore, result from non-dopaminergic lesions. Secondly, the effect of levodopa treatment on the motor symptoms was evaluated. This permitted an assessment of the relative severity of dopaminergic and non-dopaminergic lesions in the patients (see "Methods"), which could be correlated with neuro- 
psychological test scores. The battery of neuropsychological tests (detailed below) included, in addition to standard tests of memory and intelligence, a group of tests sensitive to dysfunction of the frontal lobes.

\section{Patients and methods}

\section{A-Patients}

After exclusion of patients with severe disability who could not be taken off therapy, and those with severe dysarthria, visual disorders, mental confusion, severe depression, or inability to cooperate, 120 in-patients with idiopathic Parkinson's disease were retained for the study (table 1). All were under treatment with levodopa (mean daily dose, $878 \pm 33 \mathrm{mg}$; mean duration of treatment, $5 \cdot 2$, SEM 0.4 years) plus a peripheral dopa-decarboxylase inhibitor. All other antiparkinsonian drugs were withdrawn. Levodopainduced abnormal involuntary movements were observed in 57 patients and severe fluctuations in performance in 49 .

\section{$B-$ Evaluation of motor performance}

Parkinsonian motor disability was evaluated after treatment was interrupted. The period of withdrawal varied from 18 hours in patients with severe on-off phenomena, to 6 days in the least affected subjects. ${ }^{21}$ Global motor disability (hereafter termed basal score) was assessed on a scale of 0-92 (modified Columbia scale). ${ }^{22}$ Akinesia, tremor and rigidity were each scored from 0 to 20 , and gait disorder and dysarthria from 0 to 4 . In order to permit comparison of patients with differing disease durations, the ratio of the basal motor score to the duration of the disease (hereafter termed rate of deterioration) was calculated for each subject. ${ }^{23}$

Motor performance during levodopa treatment was evaluated 2 hours after the patients received their usual morning dose, 1 to 10 days after therapy was resumed: that is, when the effect of the drug was considered to be maximal and stable. ${ }^{21}$ The Parkinsonian score under treatment (hereafter called treated score) reflects residual motor symptoms unalleviated by levodopa and, presumably, therefore, is the result of non-dopaminergic lesions in the brain. The difference between the basal score and the treated score (hereafter called the levodopa responsive score) provides an index of levodopa-sensitive symptoms, thought to result from lesion of dopaminergic neurons. The rationale behind

\section{Table 1 Characteristics of the Parkinsonian syndrome}

\begin{tabular}{|c|c|}
\hline $\begin{array}{l}\text { Age at onset (yr) } \\
\text { Duration of the disease } \\
\text { Stage* }\end{array}$ & $\begin{array}{l}55 \cdot 4,1 \cdot 1(22-77) \\
6 \cdot 9,0 \cdot 5(0.3-24) \\
2 \cdot 7,0 \cdot 1(1-5)\end{array}$ \\
\hline $\begin{array}{l}\text { Basal motor scores } \\
\text { total score } \\
\text { subscores }\end{array}$ & $28 \cdot 9,1 \cdot 3(7 \cdot 5-62)$ \\
\hline $\begin{array}{l}\text { akinesia } \\
\text { rigidity } \\
\text { tremor } \\
\text { gait disorder } \\
\text { dysarthria } \\
\text { treated motor score } \\
\text { levodopa-responsive score } \\
\text { per cent improvement }\end{array}$ & $\begin{array}{l}8 \cdot 0,0 \cdot 4(0-17 \cdot 5) \\
6 \cdot 0,0 \cdot 3(0-15 \cdot 5) \\
6 \cdot 1,0 \cdot 4(0-12) \\
1 \cdot 7,0 \cdot 1(0-4) \\
1 \cdot 3,0 \cdot 1(0-3 \cdot 5) \\
13 \cdot 9,0 \cdot 9(1-51) \\
15 \cdot 0,1 \cdot 0(6-42) \\
51 \cdot 9,0 \cdot 9(25-88)\end{array}$ \\
\hline
\end{tabular}

Data are the mean, SEM. Extreme values are indicated in brackets. ${ }^{*}$ Hoehn and Yahr. ${ }^{20}$ the use of the levodopa responsive score, as well as its limitations, have been discussed in detail elsewhere. ${ }^{24}$

\section{C-Neuropsychological assessment}

The following tests of intellectual function and memory were selected because they involve minimal motor activity: the digit span, similarities and arithmetic tests from the WAIS verbal scale; a visuospatial task, the Raven 47 coloured progressive matrices (PM-47); the Wechsler memory scale.

Patients were allowed unlimited time to perform the tests. The individual scores for each patient were summed to obtain an index of his global efficiency. In addition, an index of deterioration, ${ }^{25}$ relating the performance of the patients on the neuropsychological tests to the performance that would have been expected of them, given their age and level of education, was calculated according to the formula

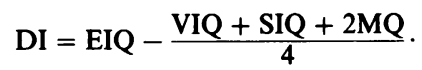

EIQ, the global expected IQ, was clinically evaluated, using norms for different ages and levels of education in a control population corrected by the best performance method. ${ }^{26}$ VIQ, SIQ and MQ, verbal and visuospatial IQs and memory quotient, respectively, were obtained by transforming the scores on the verbal tests, the PM-47 and the Wechsler memory scale. The mean and standard deviation for each item in the formula was $100,15$.

Linguistic functions were studied by object naming, dictation of a sentence and calculations. Performance of gesture was evaluated by cube copying and the execution of symbolie gestures.

Tests sensitive to frontal lobe dysfunctions included: the simplified version of the Wisconsin card sorting test, ${ }^{27}$ के 응 verbal fluency test (names of animals in one minute, word beginning with $\mathrm{M}$ in one minute), ${ }^{28}$ and a graphic series. Behavioural abnormalities (prehension, imitation, utico. isation) observed in subjects with frontal lobe lesions ${ }^{30}$ weret also noted.

\section{D-Statistical analysis}

Statistical analyses were performed on raw scores. Both linear correlations and stepwise multiple regressions ${ }^{31}$ were used to analyse the data.

\section{Results}

The scores of the 120 patients on the neuropsychological tests are presented in table 2 . Their performances on the memory and intelligence tests was within the mean of a normal age-matched population. However, the deterioration index (table 2) showed that their scores were approximately 16 points (that is, more than one standard deviation) lower than the performance expected of them from their level of education.

The correlations between the Parkinsonian motor scores and the neuropsychological tests are presented in tables 3 (global scores) and 4 (subtests of memory and frontal lobe function). Most of the neuropsychological scores were significantly and negatively correlated with the age of the patients at the onset of the 
Table 2 Neuropsychological performance

\begin{tabular}{ll}
\hline Education (yr) & $10 \cdot 5,0 \cdot 1(8-18)$ \\
WAIS verbal scale & \\
raw scores & $27 \cdot 2,1 \cdot 1(4-48)$ \\
IQ & $96 \cdot 0,2 \cdot 7(45-140)$ \\
PM-47 & $23 \cdot 2,0 \cdot 8(4-36)$ \\
raw scores & $96 \cdot 0,2 \cdot 4(40-130)$ \\
IQ & $50 \cdot 7,1 \cdot 2(13-83)$ \\
Wechsler memory scale & $92 \cdot 0,1 \cdot 3(56-131)$ \\
raw scores & $64 \cdot 6,0 \cdot 6(28-70)$ \\
MQ & $33 \cdot 2,1 \cdot 1(1-60)$ \\
Linguistic and gesture tests (global score) & $84 \cdot 1,2 \cdot 1(22-160)$ \\
Frontal lobe tests (global score) & $15 \cdot 9,1 \cdot 3(0-60)$ \\
Global efficiency &
\end{tabular}

Data are the mean, SEM. Extreme values are indicated in brackets.

disease: the older the patient at onset, the lower the scores. When the raw scores were corrected for age and educational level by calculating the deterioration index, the correlations were no longer significant. The duration of the disease was correlated with only a few neuropsychological test scores: the global score on the tests of linguistic functions and gesture, the logical memory and visual reproduction subtests of the Wechsler memory scale, and the behavioural disorders.

All of the neuropsychological test scores were significantly correlated with the basal motor score. Some neuropsychological test scores were significantly correlated with akinesia (deterioration index, PM-47, linguistic and gesture tests, frontal lobe tests, digit repetition and logical memory subtests of the Wechsler memory scale), and rigidity (global efficiency, deterioration index, PM-47, linguistic and gesture tests, frontal lobe tests, logical memory,
Wisconsin card sorting test, behavioural disorders), but none were correlated with tremor. Strong correlations were found between most of the neuropsychological test scores and the axial symptoms, gait disorder and dysarthria. None of the neuropsychological test scores were correlated with the levodoparesponsive motor score, but all were highly correlated with the residual motor score under levodopa treatment, the treated score.

In order to determine which of the characteristics of Parkinsonism (age at onset, duration of the disease, akinesia, rigidity, tremor, gait disorder, dysarthria) best predicted the neuropsychological test scores, stepwise multiple regression analyses were performed. The gait disorder score significantly predicted global efficiency $(F=15.7 ; p<0.001)$, and scores on the linguistic function and gesture $(F=22 ; p<0.001)$ and memory $(F=14.2 ; p<0.001)$ tests. Dysarthria $(F=20.4 ; p<0.001)$ and rigidity $(F=6.7 ; p<0.05)$ significantly predicted impairment of frontal lobe function.

Stepwise multiple regression analyses were also performed to evaluate which of the items related to levodopa treatment (basal score, treated score, levodopa-responsive score; age at onset and duration of the disease) were the best predictors of neuropsychological performance. The treated score significantly predicted the impairment of global efficiency $(F=34.3 ; p<0.001)$, the deterioration index $(F=25.6 ; p<0.001)$, and scores on the verbal $(\mathrm{F}=21 \cdot 7 ; \mathrm{p}<0.001), \mathrm{PM}-47(\mathrm{~F}=34 \cdot 1 ; \mathrm{p}<0.001)$; linguistic and gesture $(F=53.7 ; p<0.001)$; memory $(F=31.4 ; p<0.001)$ and frontal lobe $(F=33.1$; $\mathrm{p}<0.001)$ tests.

Table 3 Correlations between the neuropsychological performances and the characteristics of the Parkinsonian syndrome

\begin{tabular}{|c|c|c|c|c|c|c|c|c|c|c|c|}
\hline • & $\begin{array}{l}\text { Age at } \\
\text { onset }\end{array}$ & $\begin{array}{l}\text { Duration } \\
\text { of the } \\
\text { disease }\end{array}$ & $\begin{array}{l}\text { Basal } \\
\text { score }\end{array}$ & $\begin{array}{l}\text { Rate of } \\
\text { motor } \\
\text { deterioration }\end{array}$ & Akinesia & Rigidity & Tremor & $\begin{array}{l}\text { Gait } \\
\text { disorder }\end{array}$ & Dysarthria & $\begin{array}{l}\text { Levodopa } \\
\text { responsive } \\
\text { score }\end{array}$ & $\begin{array}{l}\text { Treated } \\
\text { score }\end{array}$ \\
\hline Global efficiency & -0.33 & $-0 \cdot 15$ & -0.39 & -0.07 & $-0 \cdot 17$ & -0.21 & -0.07 & -0.34 & \begin{tabular}{|l|}
-0.32 \\
\end{tabular} & 0.02 & -0.56 \\
\hline Deterioration index & -0.07 & $0 \cdot 17$ & 0.43 & $-0 \cdot 12$ & 0.22 & 0.30 & 0.08 & 0.36 & 0.31 & 0.06 & 0.53 \\
\hline Verbal tests & $-0 \cdot 30$ & -0.09 & -0.25 & 0.08 & -0.05 & $-0 \cdot 15$ & -0.08 & -0.23 & \begin{tabular}{|l|}
-0.20 \\
\end{tabular} & 0.04 & -0.44 \\
\hline PM 47 & $-0 \cdot 30$ & $-0 \cdot 16$ & -0.45 & 0.07 & -0.24 & $-0 \cdot 27$ & 0.00 & $-0 \cdot 38$ & $-0 \cdot 36$ & -0.05 & -0.57 \\
\hline $\begin{array}{l}\text { Linguistic and } \\
\text { gesture tests }\end{array}$ & -0.09 & $-0 \cdot 21$ & -0.51 & 0.09 & -0.32 & -0.32 & -0.07 & -0.41 & -0.41 & 0.00 & -0.66 \\
\hline Memory tests* & -0.28 & $-0 \cdot 15$ & \begin{tabular}{|l|}
-0.38 \\
\end{tabular} & 0.04 & $-0 \cdot 18$ & $-0 \cdot 18$ & -0.07 & -0.34 & \begin{tabular}{|l|}
-0.31 \\
\end{tabular} & 0.04 & -0.57 \\
\hline Frontal tests* & -0.28 & $-0 \cdot 17$ & -0.42 & 0.06 & $-0 \cdot 19$ & $-0 \cdot 28$ & $-0 \cdot 11$ & $-0 \cdot 37$ & \begin{tabular}{|l|}
-0.39 \\
\end{tabular} & 0.08 & -0.53 \\
\hline
\end{tabular}

*Memory and frontal subtests are detailed in table 4.

$r \geq 0 \cdot 19-p<0.05$

$r \geq 0.25-p<0.01$

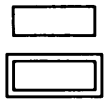


Table 4 Correlations between the memory and frontal subtest scores and the characteristics of the Parkinsonian syndrome

\begin{tabular}{|c|c|c|c|c|c|c|c|c|c|c|}
\hline & $\begin{array}{l}\text { Age at } \\
\text { onset }\end{array}$ & $\begin{array}{l}\text { Duration } \\
\text { of the } \\
\text { disease }\end{array}$ & $\begin{array}{l}\text { Basal } \\
\text { score }\end{array}$ & $\begin{array}{l}\text { Rate of } \\
\text { motor } \\
\text { deterioration }\end{array}$ & Akinesia & Rigidity & Tremor & $\begin{array}{l}\text { Gait } \\
\text { disorder }\end{array}$ & Dysarthria & $\begin{array}{l}\text { Levodopa } \\
\text { responsive } \\
\text { score }\end{array}$ \\
\hline Information & -0.09 & -0.04 & -0.23 & 0.01 & $-0 \cdot 12$ & -0.06 & 0.00 & $-0 \cdot 17$ & -0.21 & 0.03 \\
\hline Orientation & $-0 \cdot 14$ & -0.02 & -0.25 & 0.02 & -0.12 & -0.09 & 0.00 & $-0 \cdot 18$ & -0.25 & 0.05 \\
\hline Mental control & -0.18 & 0.00 & -0.21 & -0.03 & -0.13 & -0.01 & -0.02 & -0.20 & $-0 \cdot 18$ & 0.04 \\
\hline Digits & -0.15 & -0.09 & -0.32 & -0.02 & -0.25 & $-0 \cdot 13$ & $-0 \cdot 10$ & -0.20 & -0.23 & 0.02 \\
\hline Logical memory & -0.13 & -0.20 & -0.37 & $0 \cdot 12$ & -0.22 & -0.23 & -0.04 & -0.32 & -0.30 & 0.01 \\
\hline Associate learning & -0.27 & -0.13 & -0.30 & $0 \cdot 10$ & $-0 \cdot 11$ & $-0 \cdot 16$ & $-0 \cdot 10$ & -0.29 & -0.25 & 0.03 \\
\hline Visual reproduction & -0.36 & -0.21 & -0.35 & 0.04 & -0.09 & $-0 \cdot 16$ & $-0 \cdot 17$ & -0.34 & -0.25 & 0.08 \\
\hline $\begin{array}{l}\text { Wisconsin card } \\
\text { sorting test }\end{array}$ & -0.27 & -0.09 & -0.27 & $0 \cdot 10$ & $-0 \cdot 13$ & -0.23 & -0.07 & -0.30 & -0.23 & 0.02 \\
\hline Verbal fluency & -0.27 & -0.09 & -0.33 & 0.00 & $-0 \cdot 11$ & $-0 \cdot 17$ & 0.05 & -0.28 & -0.35 & 0.00 \\
\hline Graphic series & -0.14 & $-0 \cdot 16$ & -0.31 & 0.17 & -0.17 & -0.17 & $-0 \cdot 11$ & -0.24 & -0.29 & 0.05 \\
\hline $\begin{array}{l}\text { Behavioural } \\
\text { disturbances }\end{array}$ & -0.17 & -0.19 & -0.39 & -0.03 & $-0 \cdot 17$ & -0.26 & $-0 \cdot 14$ & -0.31 & -0.35 & -0.06 \\
\hline
\end{tabular}

$r \geq 0 \cdot 19-p<0.05$

$r \geq 0.25-p<0.01$

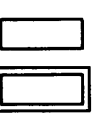

\section{Discussion}

In this study, mild but global intellectual dysfunction, including memory impairment and frontal lobe-like disorders (table 2), was observed in a large cohort of Parkinsonian patients. These results are in agreement with most previous studies on cognitive function in Parkinson's disease, reporting a broad constellation of intellectual deficits in the patients, ${ }^{3253233}$ but differ from those of Lees $e t a^{34}$ and Taylor $e t a l^{35}$ who reported that frontal lobe-like symptomatology predominates. The selection of subjects for inclusion in these studies, de novo Parkinsonians in the former, ${ }^{34}$ exclusion of patients with advanced global dementia in the latter, ${ }^{35}$ may explain the discrepancy with the present study on a less selected population which included demented patients representing the entire spectrum of the dementing process. ${ }^{36}$ This choice of patients was necessary, however, in order to explore the predictive value of clinical variables for the types of neuropsychological disorders observed in the patients.

Most of the neuropsychological performances were negatively correlated with the age at onset of the disease, indicating that the incidence of intellectual deterioration was higher in patients who were older when the disease became manifest. This confirms several previous studies. ${ }^{37-39}$ However, when the scores of the neuropsychological tests were corrected for age (deterioration index, table 3), the correlations between age at onset and test performance were no longer significant. This raises the question as to whether the more severe cognitive impairment observed in lateonset Parkinsonism corresponds to a specific subtype of the disease, as suggested by Lieberman et $a l,{ }^{37}$ or whether it results from the consequences of aging, independent of the disease process.

There were only weak correlations between neuropsychological performance and disease duration, and no correlations at all between neuropsychological performance and the rate of motor deterioration, given by the ratio of the degree of motor disability (basal score) and the duration of the disease. The evolution of motor disability is, therefore, a poor predictor of the patients' intellectual status.

In agreement with earlier studies, ${ }^{1363740-42}$ significant correlations were found between all the neuropsychological test scores and the severity of motor impairment in patients withdrawn from levodopa (basal score, tables 3 and 4). From these correlations, it might be inferred that both cognitive and motor symptoms result from the same pathological changes in the brain. This conclusion does not hold, however, if the motor symptoms are segregated as a function of their response to levodopa. Rigidity and akinesia, both of which respond well to 
levodopa, ${ }^{43}$ were only poorly correlated with neuropsychological performance, and tremor, not at all. Similar results for tremor and rigidity have previously been reported. ${ }^{19394144}$ Akinesia, however, has been found to correlate with neuropsychological deficits. $^{19394144}$ The poor correlations with akinesia obtained in the present study may be explained by the choice of neuropsychological tests involving a minimum of motor activity, but may also indicate that neuropsychological performance, unlike the major Parkinsonian motor symptoms, akinesia in particular, do not result in a major way from dopaminergic lesions.

This conclusion is supported by the lack of correlations between the neuropsychological test scores and the levodopa-responsive motor score (tables 3 and 4), presumed to reflect the decrease in striatal dopaminergic transmission. ${ }^{2124}$ Strong correlations were found, however, between almost all the neuropsychological functions analysed and axial symptomatology including gait disorder and dysarthria, which are relatively unresponsive to levodopa. A similar finding was reported by Zetusky et al, ${ }^{39}$ using a simplified mental status examination, graded from 0 to 4. Once again, this may indicate that impairment of neuropsychological performances may be related to non-dopaminergic lesions. The significant correlations observed between neuropsychological test scores and the residual motor deficits in treated patients (treated score) (tables 3 and 4) are consistent with this interpretation.

Taken together, these data strongly suggest that cognitive disturbances in Parkinson's disease are related to non-dopaminergic lesions. Abnormalities in several other neuronal systems have also been found in Parkinsonian patients. ${ }^{10}$ Firstly, there is good evidence that several subcortico-cortical systems, including the cholinergic septo-hippocampal and innominasto-cortical pathways, the noradrenergic coeruleo-cortical neurons, the dopaminergic mesocorticolimbic system and the ascending serotoninergic neurons, are the sites of lesions. ${ }^{4}$ Relationships between lesions of the cholinergic ${ }^{45-48}$ and noradrenergic ${ }^{49}$ systems and intellectual impairment in Parkinsonian patients have been demonstrated. Secondly, degeneration or dysfunction of some intracortical neurons, evidenced by the presence of neurofibrillary tangles or decreases in cortical peptide concentrations, may also contribute to dementia in Parkinsonian patients. ${ }^{4050}$ The participation of other neuronal systems in the pathophysiology of intellectual deterioration in Parkinsonian patients cannot, however, be excluded. The significant correlations observed between the whole spectrum of cognitive deficits in Parkinsonian patients and the axial symptoms, dysarthria and gait impairment, sug- gest that the lesions responsible for the latters may also contribute to the former. If so, the nature and the location of the lesioned neurones remain to be determined. Finally, intellectual deterioration and axial symptomatology, strongly correlated in the present study, do not seem to result from dysfunction of dopaminergic mechanisms. These symptoms, which do not respond to levodopa treatment, constitute a syndrome that becomes progressively more difficult to manage in the course of the disease.

The statistical analyses were performed by $M$ Blanc, Department of Biophysics and Biomathematics, C.H.U. Pitié-Salpêtrière, and S Pega, INSERM U.289. Dr G Cusimano was the recipient of a grant from the "CNR" (Rome).

\section{References}

1 Mayeux $R$, Stern $Y$. Intellectual dysfunction and dementia in Parkinson's disease. In: Mayeux $\mathrm{R}$, Rosen WJ, eds. The Dementias. New York: Raven Press 1983:211-27.

2 Mortimer JA, Christensen KJ, Webster DD. Parkinsonian dementia. In: Frederiks JA, ed. Neurobehavioural Disorders. Handbook of Clinical Neurology, vol. 46. Amsterdam: Elsevier Science Publishers 1985:371-384.

3 Brown RG, Marsden CD. Neuropsychology and cognitive function in Parkinson's disease. In: Marsden CD, Fahn S, eds. Movement Disorders 2. London: Butterworth 1986:99-123.

4 Ruberg M, Agid Y. Dementia in Parkinson's disease. In: Iversen L, Iversen SD, Snyder SH, eds. Handbook of Psychopharmacology, vol. 20: Psychopharmacology of the Ageing Nervous System. New York: Plenum Press, 1988;157-206.

5 Loranger AW, Goodell H, Lee JE. Levodopa treatment of Parkinson's syndrome. Arch Gen Psychiat 1972;26:163-8.

6 Riklan M, Whelihan W, Cullinan T. Levodopa and psychometric test performance in Parkinsonism. 5 years later. Neurology 1976;26:173-9.

7 Rogers D, Lees AJ, Smith E, Trimble M, Stern GM. Bradyphrenia in Parkinson's disease and psychomotor retardation in depressive illness: an experimental study. Brain 1987;110:761-76.

8 Delis D, Direnfeld L, Alexander MP, Kaplan E. Cognitive fluctuations associated with on-off phenomenon in Parkinson's disease. Neurology 1982;32:1049-52.

9 Mortimer JA, Pirozzolo FJ, Hansch EC, Webster DD. Relationship of motor symptoms to intellectual deficits in Parkinson's disease. Neurology 1982;32:133-7.

10 Agid Y, Javoy-Agid F, Ruberg M. Biochemistry of neurotransmitters in Parkinson's disease. In: Marsden CD, Fahn S eds. Movement Disorders 2. London: Butterworth 1987: 166-230.

11 Stern Y, Langston JW. Intellectual changes in patients with MPTP-induced parkinsonism. Neurology 1985;35:1506-9.

12 Burns RS, Chiveh CC, Markey SP, Ebert MH, Jacobowitz DM, Koplin JJ. A primate model of parkinsonism: selective destruction of dopaminergic neurons in the pars compacta of the substantia nigra by N-methyl-4-phenyl-1, 2, 3, 6-tetrahydropyridine. Proc Nat Acad Sci USA 1983;80: 4546-60.

13 Davis CC, Williams AC, Markey SP, et al. Chronic parkinsonism secondary to intravenous injection of meperidine analogues. Psychiatry Res 1979;179:249-54.

14 Bachman DL, Albert ML. The dopaminergic syndromes of 
dementia. In: Pilleri G, Tagliavini F, eds. Brain Pathology, vol. 1. Bern: Brain Anatomy Institute 1984:91-119.

15 Halgin R, Riklan M, Misiak H. Levodopa, parkinsonism and recent memory. J Nerv Ment Dis 1977;164:268-272.

16 Marsh GG, Markham CM, Ansel R. Levodopa's awakening effect on patients with parkinsonism. J Neurol Neurosurg Psychiatry 1971;34:209-18.

17 Brown RG, Marsden CD, Quinn N, Wyke MA. Alterations in cognitive performance and affect arousal state during fluctuations in motor function in Parkinson's disease. $J$ Neurol Neurosurg Psychiatry 1984;47:454-65.

18 Girotti F, Caralla F, Grassi MP, Soliveri P, Marano R, Caraceni $T$. Motor and cognitive performances of parkinsonian patients in the on and off phases of the disease. $J$ Neurol Neurosurg Psychiatry 1986;43:657-60.

19 Rafal RD, Posner MI, Walker JA, Friedrich FJ. Cognition and the basal ganglia. Separating mental and motor components of performance in Parkinson's disease. Brain 1984;107:1083-94.

20 Hoehn MM, Yahr M. Parkinsonism: onset, progression and mortality. Neurology 1967;17:427-42.

21 Esteguy M, Bonnet AM, Kefalos J, Lhermitte F, Agid Y. Le test a la L-DOPA dans la maladie de Parkinson. Rev Neurol (Paris) 1985;141:413-5.

22 Lhermitte F, Agid Y, Signoret JL. Onset and end-of-dose levodopa-induced dyskinesias, possible treatment by increasing daily does of levodopa. Arch Neurol 1978;35:261-3.

23 Blin J, Bonnet AM, Agid Y. Does levodopa aggravate Parkinson's disease? In: Fahn S, Marsden CD, Calne D, Goldstein $\mathrm{M}$, eds. Recent Developments in Parkinson's Disease. New York: MacMillan 1987:165-81.

24 Bonnet AM, Loria Y, Saint-Hilaire HL, Lhermitte F, Agid Y. Does long-term aggravation of Parkinson's disease result from non-dopaminergic lesions? Neurology 1987;37:1539-42.

25 Pillon B, Dubois B, Lhermitte F, Agid Y. Heterogeneity of cognitive impairment in progressive supranuclear palsy, Parkinson's disease and Alzheimer's disease. Neurology 1986;36:1179-85.

26 Lezak MD. Neuropsychological Assessment. New York: Oxford University Press, 1983.

27 Nelson HE. A modified card sorting test sensitive to frontal lobe defect. Cortex 1976;12:313-24.

28 Benton AL. Differential behavioral effects in frontal lobe disease. Neuropsychologia 1968;6:53-60.

29 Luria AR. Higher Cortical Functions in Man. New York: Basic Books 1966.

30 Lhermitte F, Pillon B, Serdaru M. Human autonomy and the frontal lobes, Part I: Imitation and utilization behaviors: a neuropsychological study of 75 patients. Ann Neurol 1986;19:326-334.

31 Anderson TW. An Introduction to Multivariate Statistical Analysis. New York: John Wiley 1958.

32 Pirozzolo FJ, Hansch EC, Mortimer JA, Webster DD, Kuskowski MA. Dementia in Parkinson disease: a neuropsychological analysis. Brain Cogn 1982;1:71-83.
33 Dubois B, Pillon B, Legault F, Agid Y, Lhermitte F. Slowing of cognitive processing in progressive supranuclear palsy. A comparison with Parkinson's disease. Arch Neurol 1988;45:1194-9.

34 Lees AJ, Smith E. Cognitive deficits in the early stages of Parkinson's disease. Brain 1983;106:257-70.

35 Taylor AE, Saint-Cyr JA, Lang AE. Frontal lobe dysfunction in Parkinson's disease. The cortical focus neostriatal outflow. Brain 1987;109:845-83.

36 Portin R, Rinne UK. Predictive factors for cognitive deterioration and dementia in Parkinson's disease. In: Yahr MD, Bergmann KJ, eds. Advances in Neurology, vol. 45: Parkinson's Disease. New York: Raven Press 1986:413-6.

37 Lieberman A, Dziatolowski M, Kupersmith M, et al. Dementia in Parkinson's disease. Ann Neurol 1979;6:355-9.

38 Elizan TS, Sroka H, Maker H, Smith H, Yahr MD. Dementia in idiopathic Parkinson's disease. Variables associated with its occurrence in 203 patients. J Neural Transm 1986;65:285-302.

39 Zetusky WJ, Jankovic J, Pirozzolo FJ. The heterogeneity of Parkinson's disease: clinical and prognostic implications. Neurology 1985;35:522-6.

40 Loranger AW, Goodell H, McDowell FH, Lee JE, Sweet RD. Intellectual impairment in Parkinson's syndrome. Brain 1972;95:405-12.

41 Garron DC, Klawans HL, Narin F. Intellectual functioning of persons with idiopathic parkinsonism. J Nerv Ment Dis 1972; 154:445-52.

42 Celesia GG, Wanamaker WM. Psychiatric disturbances in Parkinson's disease. Dis Nerv Syst 1972;33:577-83.

43 Bernheimer $H$, Birkmayer $W$, Hornykiewicz $O$, Jellinger $K$, Seitelberber F. Brain dopamine and the syndromes of Parkinson and Huntington-clinical, morphological, an\$\$ neurochemical correlations. J Neurol Sci 1973;20:415-55.

44 Marttila RJ, Rinne UK. Dementia in Parkinson's disease. Act Neurol Scand 1976;54:431-41.

45 Sadeh M, Brahim J, Modan M. Effects of anticholinergic drugs on memory in Parkinson's disease. Arch Neurol 1982;39:666- $\%$ (D)

46 Perry RH, Tomlinson BE, Candy JM, Blessed G, Foster JF? Bloxham CA, Perry EK. Cortical cholinergic deficit in meno tally impaired parkinsonian patients. Lancet 1983;ii:789-90.

47 Dubois B, Ruberg M, Javoy-Agid F, Ploska A, Agid A subcortico-cortical cholinergic system is affected in Parkinson's disease. Brain Res 1983;288:213-8.

48 Dubois B, Danze F, Pillon B, Cusimano G, Lhermitte F, Agid Y. Cholinergic-dependent cognitive deficits in Parkinson's disease. Ann Neurol 1987;22:26-30.

49 Cash R, Dennis T, L'Heureux R, Raisman R, Javoy-Agid F, Scatton B. Parkinson's disease and dementia: norepinephrine and dopamine in locus coeruleus. Neurology 1987;37:42-46.

50 Agid Y, Ruberg M, Dubois B, Pillon B. Anatomoclinical and biochemical concepts of subcortical dementia. In: Stahl SM, Iversen SD, Goodman E, eds. Cognitive NeurochemistryAssessment Techniques and Research Strategies for Human Neuropsychology. London: Oxford University Press, 1987: 248-71. 